2020, Volume 10, International Conference Globalization, Innovation and Development. Trends and Prospects (G.I.D.T.P.), pages: 241-251 | https://doi.org/10.18662/lumproc/gidtp2018/27

\section{Impact of Leadership Team Values and Performance on Organizational Behavior}

\section{Ion STEGĂROIU ${ }^{1}$, Valentin RADU ${ }^{2}$, Hamit SIMSEK ${ }^{3}$, Alina Iuliana TĂBîRCĂ* ${ }^{4}$}

${ }^{1}$ Valahia University of Targoviste, Romania, stegaroiuion@yahoo.com

2 Valahia University of Targoviste, Romania, valuradu@yahoo.com

${ }^{3}$ Valahia University of Targoviste, Romania, hamit75@yahoo.com

${ }^{4}$ Valahia University of Targoviste, Romania, alina_tabirca@yahoo.com Corresponding author
Abstract: The authors investigated the relationship between leadership team values and organizational behaviour, form a theoretical point of view. Due to the fact that we live in an era of continuous change, in which the technology surprises us every day, which passes more and wherever we want it or not, we must respond to these fluctuations. For people to survive, they have to adapt to the circumstances and events around them. If they seek to evolve and of course develop, the human species must make major changes and face all kinds of attempts. It's not just that changes are taking place at an increasingly rapid pace. The future itself no longer has the same conception as in the past. Drucker states that "All institutions exist and operate in two periods of time: today and tomorrow. The future is preparing today and is often irrevocable. That is why managers have to organize both the present and the future. In times of change, managers do not have to imagine that the future is a continuation of the present. On the contrary, they have to turn to change and change, both as an opportunity and as a threat." Building a high performing, values-driven team that utilizes the strengths of its members requires commitment and an ongoing process of values management that becomes deeply ingrained into the ethos of the team. In this article we will analyse what is not working. We provide you with an overview of what drives your leaders, how they work together, and what they want to build on or develop for the future.

Keywords: performance; organisation behaviour; leadership; team values.

How to cite: Stegăroiu, I., Radu, V., Simsek, H., \& Tăbîrcă, A.I. (2020). Impact of Leadership Team Values and Performance on Organizational Behavior. In I. Panagoreț \& G. Gorghiu (vol. ed.), Lumen Proceedings: Vol. 10. International Conference Globalization, Innovation and Development. Trends and Prospects (G.I.D.T.P.) (pp. 241-251). Iasi, Romania: LUMEN Publishing House.

https://doi.org/10.18662/lumproc/gidtp2018/27 


\section{Introduction and generalities related to organizational change}

Starting from the general concept of change defined by French and Bell as just "a new state of things different from the old state of affairs" [1], organizational change is more difficult to define. An easier approach to better understanding would be a comparison with other types of change. The very name of organizational change does not offer a varied palette of descriptions on this subject, thus, by comparing the operational and the organizational change, we can see that the former refers exclusively to individuals, their roles and values, while the one the latter covers a much broader field, namely all operational processes: customer service, production and logistics . In addition, organizational change also covers changes in work processes (which can be understood as "a set of tasks performed to achieve a clear goal"[2]) and their subsystems.

Another interesting approach embraces the organizational change in the category of "transition states between the current state and a future state to which the organization tends" [3]. The definition starts from the concepts of Lewin [4], who formulated the concept of movement between two discrete and somehow immutable "states" as organizational change, that is, being in the state I at the moment I and into state II at moment II. The suggested movement is a linear and static one and, according to some authors, does not fit the dynamic concept of organizational change because it greatly simplifies a very complex process, but that is precisely why it offers a very direct possibility to plan the actions of change [5], [19].

In addition to the processes mentioned above, the organizational change also includes the real content of the change that takes place within them. Moreover, we must not omit the context in which organizational change occurs. This is equally important, because „to formulate the content of a strategy must be controlled both by the context in which it takes place and by the process in which it takes place" [6]. In another direction, strategic change becomes an interaction between the ideas about the context, the process and the content of change, and all analyzes that do not take this into account and regard any organizational change as an individual fact, not actually analyzing the form, the meaning and the substance of change.

Secondly, the causes that lead to the emergence of change are also a defining element of this concept. These mainly represent the radical and paradigmatic change known as the "second order change" [7]. Continuing the idea of comparison presented above, organizational change can easily be compared to or even considered an innovation. Innovation can be defined 
as a technology, product or practice "used for the first time by members of an organization, regardless of the fact that it has already been used in other organizations"[8].

We can therefore conclude that the success of organizational change depends both on the quality of the solution found and on the effectiveness of its implementation, which can have three consequences: effective implementation, use of innovation or change (interchangeable in the context) improves the performance of the organization; effective implementation, but the performance of the organization is not affected in any way; implementation is unsuccessful.

As we can see above, the effects of change can be negative if the solutions found are bad or inappropriate to the context, which only highlights the lack of interdependence between the content and the process of change. This is also the point of view of the strategic study school that relies most on content, and the premise of change is the predefined state to be implemented [9]. There are often situations where implementation leads to lower performance. Organizational change must therefore promote an organization's evolution strategy, which is obvious that it cannot be constant but dynamic. There are many ways to look, from the practical point of view, to the issue of change in an organization. What is specific to any organization is the precarious balance, the continuing occurrence of tensions, problems.

Some people talk about change with great enthusiasm, while others see it as a threat. Many of us are ambivalent: we consider changing at the same time, both good and bad. Generally, change involves risk, uncertainty and disorder. However, our attitude and the way we perceive change have a defining role in our evolution, both individual and collective. The ambivalence mentioned above is highlighted in the entire management literature, and the change is described in very dynamic and favorable terms. Change management is presented as a process designed to turn those skeptical or prudent into true followers of a glorious cause.

\section{Theoretical Background on Organizational Development and Change}

When discussing the subject of organizational change, we focus on the importance of organizational development and behavior. This is one of the basic concepts for dealing with organizational change.

First of all, this notion has appeared relatively recently in the field of organizational terminology (the '70s) and, as any term of social science, has 
known and knows a whole range of definitions and concepts. Bennis [10] said that: "organizational development is a response to change, a complex educational strategy that aims to change the organization's norms, values, attitudes, and structure so that it can better adapt to new technologies, new market challenges, and the dizzying rate of contemporary change." Another definition given by Schmuck and Miles in 1971 claims that "organizational development can be defined as a planned and sustained effort to apply behavioral sciences to improve the system using reflexive, self-analytical methods"[15]. "Organizational development is a set of theories, values, strategies and techniques based on social sciences and behavior that want to implement a planned change in organizational work in order to improve individual development and enhance organizational performance by altering the behavior of members of the organization in the workplace"[16].

There are three dimensions of this concept that are taken into account: problems that may arise in an organization; the level at which they occur: individuals, pairs, groups or teams, intergroup, organizations; interventions that can be performed. Secondly, one of the most solid theoretical foundations in the field of organizational change is system theory. Starting from this premise, organizations are open systems engaged in exchanging matter, energy and environmental information. The model of planning was developed by Lippitt, Watson and Westley [11] and is based on two axiomatic assumptions: information must be freely shared by the organization and agent of change; information is useful only when it can be translated into action.

Although it is easy to note that organizational development and organizational change are two different concepts, confusion is not delayed. So, organizational change is only an instrument of organizational development used to increase the effectiveness of the organizational system. From this, we can easily deduce that organizational development is a process that takes a longer time than a simple organizational change. Moreover, we must not overlook the fact that organizational development is a complex, multi-dimensional process that articulates in a coherent whole more organizational changes.

Moreover, we start from an extremely important aspect of Beckhard's idea that organizational development implies the involvement of top management. Practically, starting from this idea, we can consider that we are targeting the change of the whole organization, changing how it relates to the environment, how it works, and how it is structured. Organizational change itself is a multidimensional process that takes place along several axes and directions. 
In other terms, it is not enough to have organizations that have a low resistance to change, which are pro-change (as a structure and culture); we need organizations capable of dealing, being autonomous, self-aware and solving problems, organizations with a high degree of adaptability that can learn from their own mistakes. Changing productive activity (whether material or symbolic), communication, management, etc. is related to the cultural dimension of the organization, to the norms and values that direct and structure the activity of members of any organization. According to Leavitt's theory, a change in any field of the organization affects all the dimensions of that social system, so any change affects (obviously, in a different way) the organizational culture. Moreover, in order for the re-life phase to be successful, the new situation, the new organizational reality must be absorbed by the organizational culture, its values and norms having to be synchronized with the post-change state of the organization.

Without a doubt, we can definitely say that today, the basis of the work of any modern organization is no longer the individual, but the working group. We are increasingly discussing group efforts, group values and norms, group achievements, and that is why an organization that aims to resist the current environment must base its entire structure and activity on groups, work teams. Building on these ideas, organizational development is a long-term process initiated and conducted by the organization's leadership, focusing on "organizational learning" and problem-solving, integrating all organizational dimensions, and "motoring" group of members of the organization.

We conclude with the idea that the cultural dimension improves trust, communication, sharing of information and willingness to accept change - conditions that must precede any effort of change if we want it to be successful. In addition, managerial skills provide human resources management with new ways to solve complex problems and "ditch" hidden prejudices by members of the organization. In addition to the extremely important managerial skills, cooperative organization is also defining. The latter, generating the construction of the working teams, and with them, the insertion of a new culture, of new attitudes and skills that will facilitate the solving of the complex problems. In fact, the strategy-structure dimension means creating a new strategic plan for the organization (or improving existing ones) and aligning departments, offices, workgroups, and individual positions to support the new strategic direction. The reward system establishes a merit system based on performance rewarding that supports change and new working methods by legitimating (officially) the new culture, new management practices and the new group work system. 


\subsection{The resistance to change}

The pressure exerted on organizations to change is permanent, that is why the relation between the resistance to change of individuals and the organization is practically inevitable. British author Leigh A. believes that "any behavior that attempts to maintain the status quo in the face of pressures that try to modify it" [17] can be considered a resistance to change. Generally, the phenomenon of resistance to change in organizational space is described as an irrational, counter-productive behavior of a minority within the organization, with negative consequences on the whole system.

We state that the resistance to change of the individual has a major impact on leadership team values due to different attitudes as the attention and the selective memory, the habit, the evocation of the past and the security, the dependence, the economic reasons and the fear of the unknown, as stated by Duică [12]. These can also be seen in Figure 1.

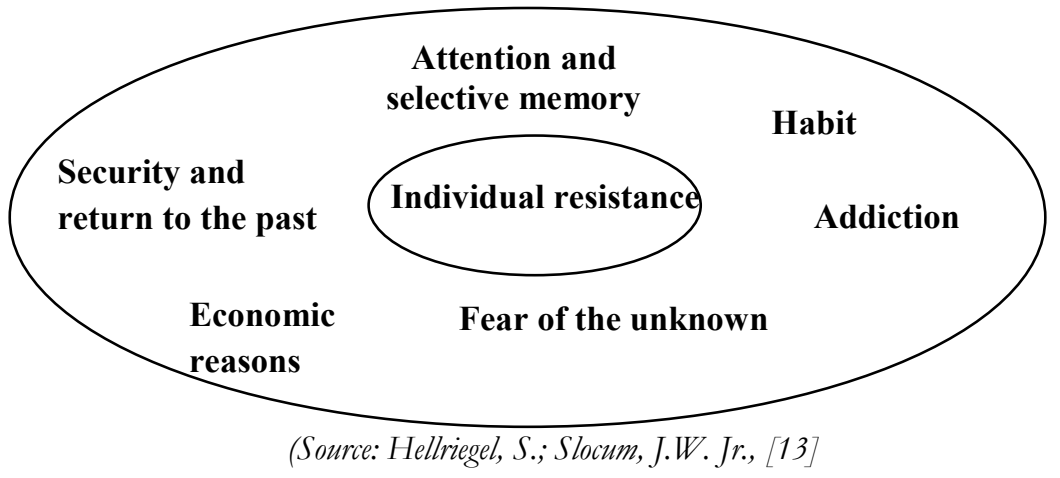

Figure 1. Causes of individual resistance to change

To be able to discuss the resistance to change of an individual, of an organization, we think it is extremely important to make a more detailed analysis of the field of forces. As consumers, we tend to perceive very quickly the changes that take place within an organization, and so we have the opportunity to discover that they have a far more powerful effect on those working in those organizations. Because the changes are neither bad nor good what is really important is the way they are implemented and managed for both customers and members. K. Lewin [4] believes that changing as a dynamic balance of forces which, on the one hand, put pressure on change, and on the other hand, it provokes resistance to change. 


\begin{tabular}{|c|c|c|}
\hline $\begin{array}{l}\text { Elements that cause } \\
\text { change } \\
\text { (pressure to change) }\end{array}$ & \multirow{8}{*}{ BALANCE } & $\begin{array}{l}\text { Elements that inhibit } \\
\text { change } \\
\text { (obstacles to change) }\end{array}$ \\
\hline Technological change & & Obsolete mentalities \\
\hline $\begin{array}{l}\text { The explosion of } \\
\text { knowledge }\end{array}$ & & Mental blocking \\
\hline Aging products & & Disinterest \\
\hline \multirow{4}{*}{$\begin{array}{l}\text { Improving working } \\
\text { conditions }\end{array}$} & & Fear of the new \\
\hline & & Fear of failure \\
\hline & & $\begin{array}{l}\text { The low degree of } \\
\text { professionalism }\end{array}$ \\
\hline & & $\begin{array}{l}\text { Changing the structure of } \\
\text { the workforce }\end{array}$ \\
\hline
\end{tabular}

(Source: P., Marinescu, 2003 [14])

Figure 2. Force Field Analysis after K. Lewin

We consider that the use of this model has substantial advantages. Firstly, the model forces managers to analyze in detail the situation they are in, so it is easier to diagnose opposing forces or those that are favorable to change. A clear and profound perception of the need for change by the managers of the organization is indispensable to the process of change. Second, the model highlights changeable factors and those that cannot be changed.

\section{Mentoring and Coaching the key concepts for maximize performance}

In order for the organization to survive the challenges of the external environment, to gain competitive performance and competitive edge on the market, we consider that it must develop as much as possible skills, competences and knowledge of its employees.

The purpose of coaching is to correct inappropriate behaviors, improve performance, and share skills the employee needs to accept new 
responsibilities. The one who guides learning and training is the coach and he is the one who says/indicates and offers adequate feedback. Coaching is a process that develops in the short term, focusing on immediate needs, based on the "in case of need ". As we stated above, coaching means evolution and performance. Because people need to always improve their performance, coaching is an extremely easy way to do that. Parallel to the training, CIPD (https://www.cipd.co.uk/knowledge/fundamentals/relations/engagement/ employee-outlook-reports) reported, following a study, that $99 \%$ of respondents surveyed responded that coaching programs deliver tangible benefits to individuals and organizations; $93 \%$ said that the coaching process is a transfer tool for learning at work; $92 \%$ agreed that when the process is managed efficiently, it can have positive effects; $96 \%$ said the process is an effective way to promote organizational learning [18]. Another study conducted in 2006 by the CIPD also showed that $72 \%$ of the subjects agreed that the coaching process is the first tool to help increase productivity and performance.

As benefits for the organization, we will declare that coaching it brings an improvement in the final profit margin due to lower production costs. It also attracts people who are looking for a job by providing their development. Another benefit would be that shareholders are satisfied with the improvement in the financial situation. Among the manager's benefits: work performed according to standards, existence of subordinates who want to work for him, getting a higher workload from the subordinates, lowering the level of personal stress, etc.

We must not forget about the subordinates' benefices. They are more enthusiastic about their work, more motivated, and will show an increase in control over their work. I also live in the belief that she is working for a manager who cares about them.

As a disadvantage, if we compare the training sessions, we can say that in the case of coaching, the cost is higher because it works one-on-one.

Mentoring plays a very important role in developing human potential and improving individual and organizational performance. There are several types of coaching and mentoring depending on style and organization that are designed to meet the needs of learners in various sectors of activity. In Eastern Europe, coaching and mentoring are not very much used. Therefore, we are talking more about an art than about a science. Mentoring is a transfer of knowledge and wisdom from one person to another. It is a process that takes place over a longer period of time and a strong emphasis is placed on listening, providing a role model, and providing socioprofessional suggestions and relationships from mentor to disciple. 
If we were to compare the relationship between a coach and an employee, I could say that the relationship between mentor and employee is tight, based on friendship, and this is because mentoring occurs in all areas of society, even in the work of volunteering. The mentor is the person who encourages, advises and supports career development. At the same time, he provides practical assistance to ensure that you are able to achieve your professional and personal development goals.

One of the outstanding benefits of the mentoring process is the cost effectiveness. More specifically, by comparing traditional learning methods, both coaching and mentoring are much simpler, more efficient and cheaper, while providing electronic support. This has also been demonstrated through the CIPD study that over $50 \%$ of managers have demonstrated that coaching and mentoring programs are more effective than traditional ones.

\section{Conclusions}

Change must be understood as a continuous goal, which, by fulfilling it, any organization can adapt to internal and external fluctuations, and leadership, team and team synergy are just means to achieve this. So, choosing a proper leadership style, motivating teamwork, creating synergy between leadership vision and team implementation capability, the organization can generate the positive change it wants.

Another advantage is given by rapidity in the sense of rapid learning methods (coaching and mentoring) that more and more managers are calling for results. According to a CIPD study conducted on a sample of 800 training managers from UK, $87 \%$ of them now use coaching and mentoring.

Another strong point is that organizations continue to offer, with the help of these programs, not only practical help but also support for the employees, giving them the chance to grow, to be more motivated and to evolve. We find some disadvantage like stereotypical ideas, lack of mentoring programs, lack of knowledge and skills of mentors and all of them affect the development of the individual and not only. Another weak point would be the ego, the importance and self-interest affecting organizations, and last but not least, the machiavelic behavior obsessed with power, which is a real obstacle.

In conclusion, the change is in each of us, or more precisely, the change we are, the inhabitants of this planet. We believe that as long as we are able to understand the change and accept it with the advantages and disadvantages it brings, then our path to evolution will surely gain new valences. Being a manager is not easy, in the end nothing of what is beautiful 
is not easy in life, that's why it is important to know first and see success as a challenge we have to overcome by the team we have created and developed as a coach or mentor.

\section{References}

[1]. French W, Bell HC. Organization Development. Behavioral Science Interventions for Organization Improvement. 6th ed. New Jersey: Prentice Hall; 1999: 22. [ISBN 9780132422314]

[2]. Davenport TH, Short JE. The New Industrial Engineering: Information Technology and Business Process Redesign. Sloan Management Review. 1990; 31:11-27.

[3]. Cummings TG, Worley CG. Organization Development \& Change, 9th Edition. South-Western, a part of Cengage Learning; 2008.

[4]. Lewin K. Field Theory in Social Science. New York: Harper \& Row; 1951.

[5]. Cooperrider D, Whitney D A Positive Revolution in Change: Appreciative Inquiry. In: Cooperrider D, Sorensen P, Whitney D, and Yaeger T (eds.) Appreciative Inquiry: Rethinking Human Organization Toward a Positive Theory of Change. Champaign, Ill.: Stipes Publishing, 2000): 3-28;

[6]. Pettigrew A, Starkey K, Hambrick, D. Power and Change: Andrew Pettigrew on Strategy and Change. The Academy of Management Executive (19932005). 2001;15(3): 45-47.

[7]. Levy A. Second-order planned change: Definition and conceptualization. Organizational Dynamics. 1986; 15(1): 5-23. https://doi.org/10.1016/00902616(86)90022-7.

[8]. Nord WR., Tucker S. Implementing routine and radical innovations. Lexington Books; 1987.

[9]. ManIntosch R, MacLean D. Conditioned Emergence: a Dissipative Structures Approach to Transformation. Strategic Management Journal. 1999; 20: 297316.

[10]. Bennis WG. The Temporary Society. Journal of Creative Behavior. 1969; 3(4): 223-242. https://doi.org/10.1002/j.2162-6057.1969.tb00057.x .

[11]. Lippitt R, Watson J, Westley B. The dynamics of planned change. New York: Harcourt, Brace \& Company; 1958: 8, 312.

[12]. Duică A. Management. Târgoviște: Bibliotheca, 2008.

[13]. Hellriegel S, Slocum JW Jr. Management, Seventh Edition. Ohio: SouthWestern College Publishing; 1996.

[14]. Marinescu P. Managementul instituțiilor publice. Bucharest: Universităţii Publishing House from Bucharest; 2003.

[15]. Schmuck RA, Miles MB. Organization development in schools. Michigan University; 1971.

[16]. Porras JI, Robertson PJ. Organizational development: Theory, practice, and research. In: Dunnette MD, Hough LM. (eds.) Handbook of industrial and organizational psychology. Consulting Psychologists Press; 1992: 719-822. 
[17]. Leigh, A. Effective Change. London: Institute of Personnel Management; 1988.

[18]. https://www.cipd.co.uk/knowledge/fundamentals/relations/engagement/em ployee-outlook-reports, Survey Employee Outlook, 2016-2017

[19]. Watkins J. Mohr, B. Appreciative Inquiry. San Francisco: Jossey-Bass; 2001. 